\title{
RESEARCH ON POPPERS USED AS ELECTRICAL CONNECTORS IN HIGH SPEED TEXTILE TRANSMISSION LINES
}

\author{
Jacek Leśnikowski \\ Technical University of Lodz, Department of Architecture of Textiles, Żeromskiego St. 116, 90-924 Łódź, Poland, lesnik@p.lodz.pl
}

\begin{abstract}
:
This paper presents results of research on poppers used as electrical connectors connecting fragments of textile signal lines. These lines can be used in intelligent clothing for connecting electronic modules implemented in it. Intelligent (smart) clothing can be used, among others, in the health monitoring of the elderly, newborn babies, or people working in hazardous conditions, for example, firefighters and soldiers. The aim of the present study was to examine the usefulness of poppers, widely used in clothing, as electrical connectors connecting parts of the textile signal lines designed for transmission of high-speed digital signals. The paper presents examples of measured parameters characterizing transmission properties of two fragments of the coplanar, textile transmission line connected to each other using conventional poppers. The presented measurement results contain the so-called $s$ parameters, characteristic impedance of the poppers, and eye measurements characterizing distortions of digital signals passing through the tested line. In the article, the effect of temperature and humidity of air surrounding the tested poppers on their characteristic impedance was also presented. This property and its stability are important in signal lines designed for high-speed data transmission.
\end{abstract}

\section{Keywords:}

smart clothing, electrical connectors, textile transmission lines, textronic clothing, e-textiles, smart textiles

\section{Introduction}

The growing popularity of wearable electronic resulted in an increased interest in the so-called smart garment also known as intelligent, textronic clothing. Such clothing is equipped with a number of electronic devices performing functions such as communication, data processing, and measurements. [1]. Possible applications of such garments are enormous, ranging from implementation of $\mathrm{mp3}$ player or GSM phone in the garment, implementation of physiological parameters monitoring systems that apply to personal protection systems against various types of threats, and ending with the medical systems [2-8]. Electronic modules arranged in such garments are usually connected to signal lines in the form of conventional cables fitted with conventional electrical connectors. In many cases, these lines must have the ability to transmit signals of high frequency or a broad frequency spectrum, for example, high-speed digital data transmission lines or lines connecting the radio transmitter with textile antenna [9-11]. Conventional lines have the most common form of coaxial cable. These cables and electrical connectors increase the stiffness and mass of smart clothing. The conducted works aim at replacing conventional transmission lines by lines made from textile materials. In the future, conventional electrical connectors can be replaced by connectors that are decoration in the garment or by mechanical connectors designed for connecting different pieces of clothing. Numerous studies concerning the possibility of use of this type of connectors in modern garment were conducted. For example, Minyoung [12] presented an idea of electrical connector for garment applications.
Another possibility is the use of conventional fasteners widely used in the garment such as poppers (snaps) as electrical connectors. The article presents some tests of the usefulness of the selected poppers as electrical connectors which are able to transmit high-frequency signals. The ability to transfer these signals allows one to use conventional poppers as an electrical connector in textile, signal lines for high-speed data transmission. In order to determine the transmission properties of poppers, selected parameters, such as $s$ parameters [13], characteristic impedance [13], and eye diagram were measured [14]. The $s$ parameters characterize the transmission properties of the line with installed poppers in the frequency domain, while the eye diagram characterizes them in time domain.

Another important parameter characterizing transmission properties of the line or electrical connectors is characteristic impedance [13]. To avoid reflections of the transmitted signal, impedance value should remain constant along the entire signal path containing transmitter, transmission line, and a receiver. Lack of this permanence causes reflections and distortion of the transmitted signal. In extreme cases, this prevents proper signal transmission. As a part of the research, measurements of characteristic impedance of poppers and effect of temperature and humidity on this parameter were made. The presented studies were aimed to determine the suitability of selected types of poppers as electrical connectors for connecting parts of textile signal lines. 


\section{Description of tested samples and test stands}

In the conducted research, two types of poppers were used:

1. Spring "12" (clasp $7,6 \mathrm{~mm})+$ top $8 \mathrm{~mm}$

2. S-spring (clasp "0"GB) + top $7.5 \mathrm{~mm}$.

Both types of poppers are shown in Figure 1.

In order to verify in real conditions the properties of the tested poppers, they are mounted on two pieces of textile coplanar signal line forming the structure shown in Figure 2.

The overall length of the structure was about $9 \mathrm{~cm}$.
This structure allows to examine the transmission properties of the poppers, taking into account phenomena occurring on the contact between popper and signal path. Textile lines are composed of non-conductive fabric and the three electroconductive paths of fabric sewn into it. Basic parameters of non-conductive fabric used as substrate of the line are shown in Table 1. Basic parameters of the electroconductive fabric used for electroconductive paths are shown in Table 2. Electroconductive paths are made from twill fabric, made from nickel metallized polyester yarns. More information about these types of lines can be found in [15-25].

For all conducted measurements, the tested structure was placed into the measurement fixture containing two terminals that enable connection between flat paths of measured

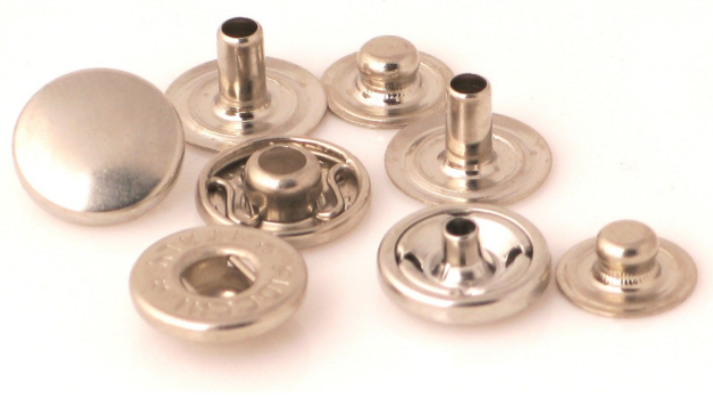

(a)

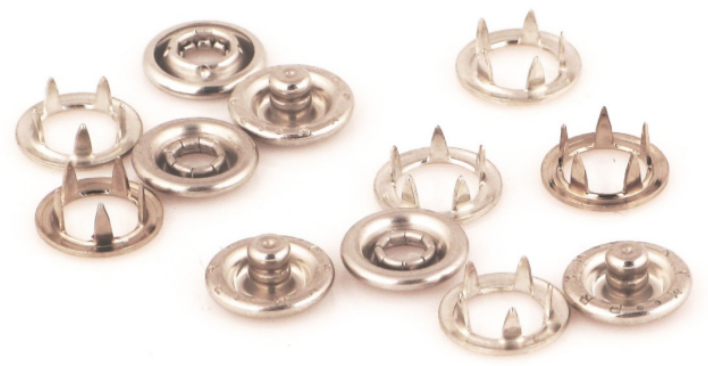

(b)

Figure 1. Poppers used in conducted research: (a) Spring and (b) S-spring

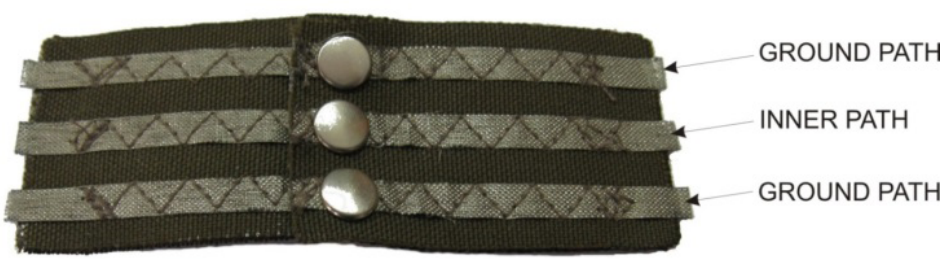

Figure 2. Tested structure

Table 1. Basic parameters of non-conductive fabric used as substrate of the line

\begin{tabular}{|c|c|c|c|c|c|c|c|c|}
\hline \multirow{2}{*}{ Material } & Weave & Thickness & $\begin{array}{c}\text { Warp } \\
\text { density }\end{array}$ & $\begin{array}{c}\text { Weft } \\
\text { density }\end{array}$ & $\begin{array}{c}\text { Mass } \\
\text { per unit } \\
\text { area }\end{array}$ & $\begin{array}{c}\text { Volumetric } \\
\text { density }\end{array}$ & $\begin{array}{c}\text { Dielectric } \\
\text { constant (f } \\
=1 \mathbf{G H z})\end{array}$ & $\begin{array}{c}\text { Loss } \\
\text { tangent } \\
(\mathbf{f}=1 \mathbf{G H z}\end{array}$ \\
\cline { 3 - 8 } & & $\mathbf{m m}$ & $\begin{array}{c}\text { yarns/ } \\
\mathbf{c m}\end{array}$ & $\begin{array}{c}\text { yarns/ } \\
\mathbf{c m}\end{array}$ & $\mathbf{g} / \mathbf{m m}^{2}$ & $\mathbf{k g} / \mathbf{m}^{3}$ & - & - \\
\hline Polyester-wool & plain & 0.64 & 21 & 15 & 188 & 427 & 1.457 & 0.009 \\
\hline
\end{tabular}

Table 2. Basic parameters of electroconductive fabric used as conductive paths of the line

\begin{tabular}{|c|c|c|c|c|}
\hline \multirow{2}{*}{ Material } & \multirow{2}{*}{ Weave } & Thickness & Mass per unit area & Conductivity of fabric \\
\cline { 3 - 5 } & & $\mathbf{m m}$ & $\mathbf{g} / \mathbf{m}^{2}$ & $\mathbf{S} / \mathbf{m}$ \\
\hline nickel metalized polyester & twill & 0.15 & $42-48$ & 221,088 \\
\hline
\end{tabular}


structure and coaxial connectors of the measuring apparatus. View of the measurement fixture with the tested structure is shown in Figure 3. All measurements were conducted in controlled temperature and humidity.

For structures described earlier, measurements of the socalled $s$ parameters were made. The measurements were made using Vector Network Analyzer ZVA40 from Rohde \& Schwar ${ }^{\circledR}$ company. For these measurements, the influence of the measuring fixture on measurement results was removed by the "Fixture compensation" option provided by analyzer. In the next step, measurements and analysis of eye diagrams were performed. An eye analysis is a well-known method and is widely described in the literature [14]. In this method, wellknown digital signal (e.g., pseudo random digital test signal) is brought to the input terminal of the transmission channel and acquiring on the sampling oscilloscope connected to the output of this channel. From obtained samples, the so-called eye diagram is created. This diagram is created from the acquired repeatedly waveforms and waveforms shifted in phase by 180 degrees. Multiple acquisition of output signal enables evaluation of short-term changes in the signal (jitter of the signal), which has a significant impact on the correctness of transmission and the value of bit error ratio (BER) [26]. The measuring stand used for this type of research is shown in Figure 4. The measurements were made using a sampling oscilloscope Tektronix DS8200 equipped with 80E08 and 80A06 modules. The pseudo random digital test signal (PRBS7) was generated by Tektronix ${ }^{\circledR}$ AWG7052 arbitrary waveform generator. The length of generated digital pattern was 127 bits. This pattern is transmitted through the tested structure. Transmitted signal was also received by $80 \mathrm{E} 08$ acquisition module. AWG7052 generator also generates a "clock" signal that is connected to the 80A06 pattern synchronization module. This module creates signal needed for proper synchronization of oscilloscope. For measurement of signal properties from acquired eye diagram, specialized software named 80SJNB was used. This software allows computation of eye diagram properties such as eye amplitude and eye opening [14]. This software also computes properties of the eye for the assumed, particular BER.

In the next research, measurements of the characteristic impedance profile were made. The profile describes impedance of the tested structure as a function of time flight of voltage wave (or distance from beginning of the structure). Such profile allows the determination of the characteristic impedance in each point of the tested structure including point where poppers were mounted. It is worth mentioning that the results of the measurements can be, if necessary, transformed to the frequency domain. The measurements were made using a sampling oscilloscope Tektronix ${ }^{\circledR}$ DS8200 equipped with an 80E08 module for impedance measurement using reflectometry (time-domain reflectometer, TDR) method [2730]. Appearance of a measuring stand is shown in Figure 5. The tested structure was placed between measuring terminals in the measuring chamber with controlled temperature and humidity. The $80 \mathrm{E} 08$ module generates voltage impulse with high slew rate and known amplitude, which propagates along the structure under test. Voltage wave reflected from locations where characteristic impedance differs from $50 \Omega$ returns to

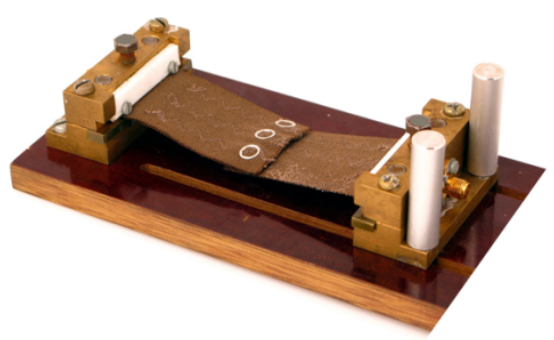

Figure 3. Measuring fixture and the tested structure

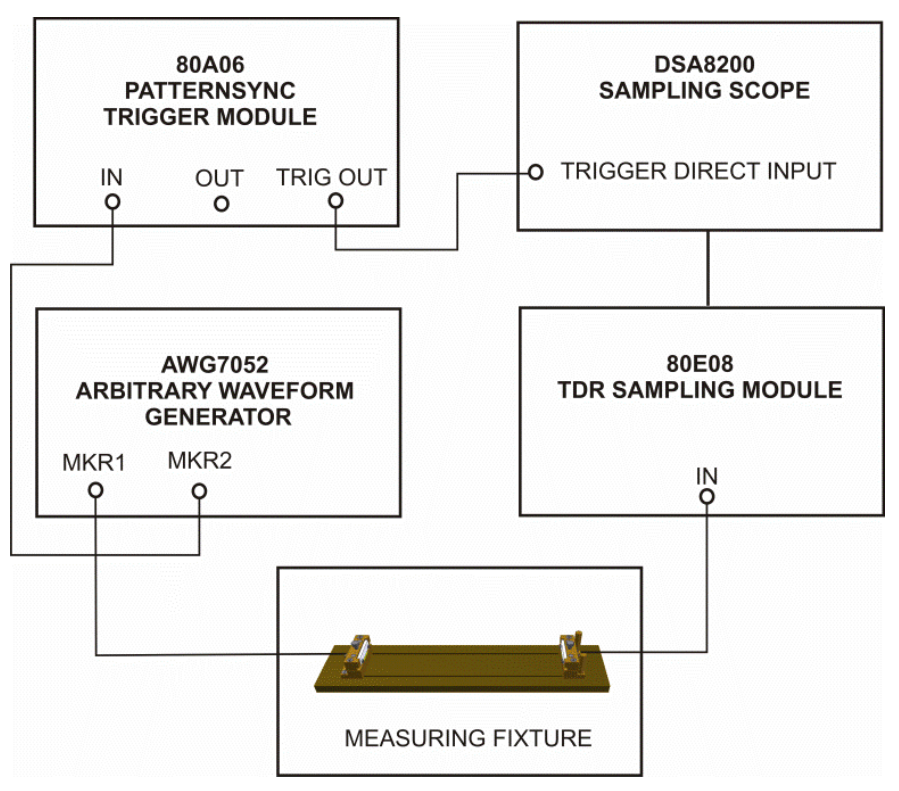

Figure 4. Measuring stand for eye measurements

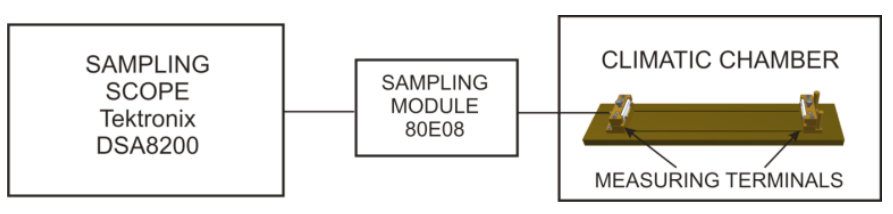

Figure 5. Measuring stand used for characteristic impedance measurements

$80 \mathrm{E} 08$ module and hence to the oscilloscope. Based on this information, IConnect $\circledast$ software installed on the oscilloscope allows the determination of the so-called real impedance profile, that is, the impedance as a function of time of travelling voltage wave, taking into account the phenomenon of multiple reflections. This time can be easily converted to distance from the beginning of the line. It allows the determination of characteristic impedance at any point of the tested structure [28]. The tests were performed for different values of temperature and relative humidity of air surrounding the tested structure. Owing to the sorption phenomena occurring in textile materials, measurements of each test structures were made after the same recondition time.

\section{Measurement results}

An example of measured impedance profile of the tested structure is shown in Figure 6. 


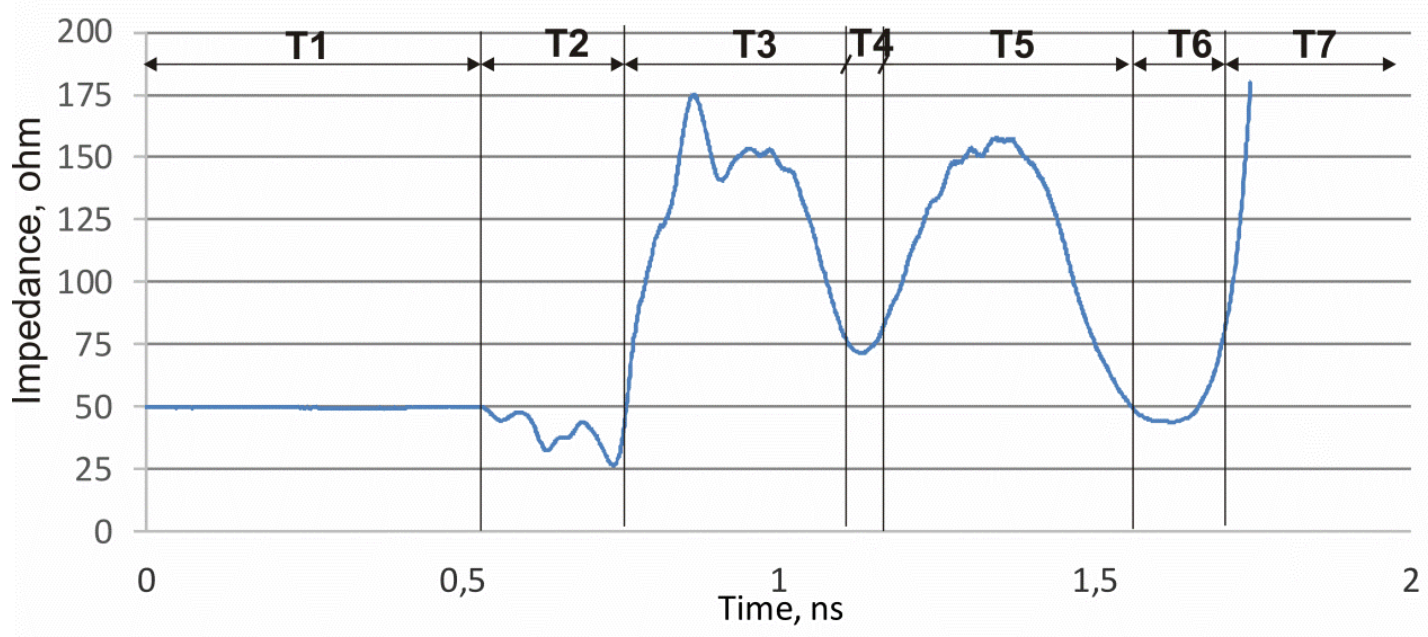

Figure 6. Average impedance profile of the popper $1\left(20^{\circ} \mathrm{C}, 65 \%\right)[31]$

Measured impedance profile of the tested structure (Fig. 6) can be divided into several time periods, whose interpretation is as follows:

- $\mid \mathrm{T} 1$ - transition time of voltage wave through the coaxial cable and RP-SMA socket,

- |T2-transition time of voltage wave through the first measurement clamp (terminal),

- |T3 - transition time of voltage wave through the transmission line located between the terminal and the popper,

- |T4-transition time of the voltage wave through the popper,

- |T5 - transition time of voltage wave through the transmission line located between popper and the second terminal,

- |T6-transition time of voltage wave through the second measurement terminal,

- |T7-reflected voltage wave at the end of the second, opened terminal.

The characteristic impedance of the tested popper was found as the minimum impedance for the time interval T4. As you can see from the profile (Fig. 6), textile signal line on which tested poppers are mounted has higher impedance than generally accepted value of $50 \Omega$ in HF measuring equipment. Tested line also has higher impedance than popper mounted on it. This is due to the large distances between the inner signal path and ground paths. These in turn are caused by the relatively large dimensions of the tested poppers. Poppers compatible with textile coplanar signal lines should have, therefore, possible small size. Otherwise obtained structure will be a source of numerous wave reflections, which may prevent correct signal transmission. The impact of this phenomenon also occurs in the results of $s$ parameters. The obtained examples of real part of $s 11$ and $s 21$ parameters are shown in Figures 7 and 8, respectively.

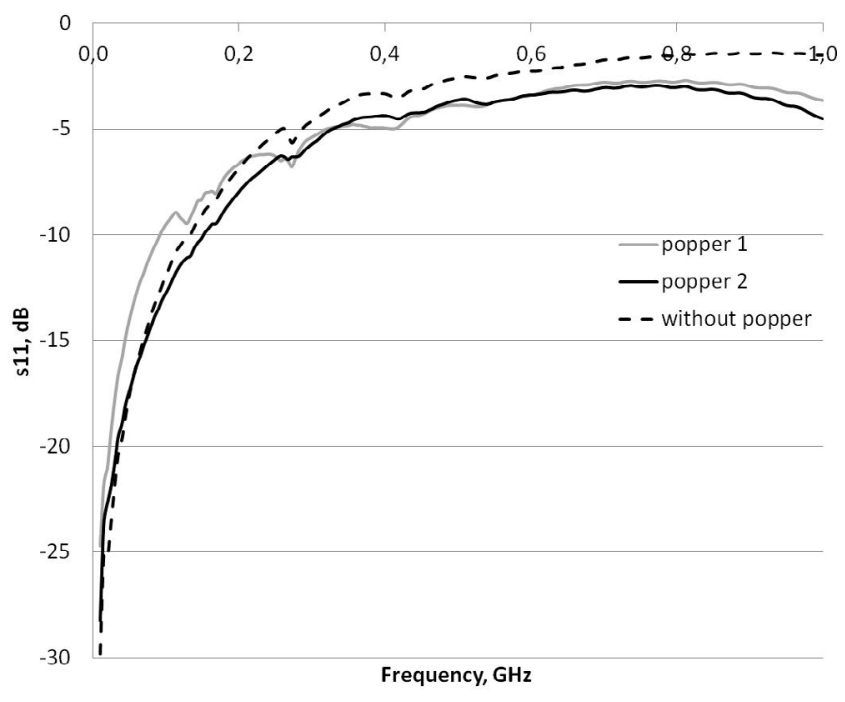

Figure 7. Real part of $s_{11}$ parameter of the tested structure

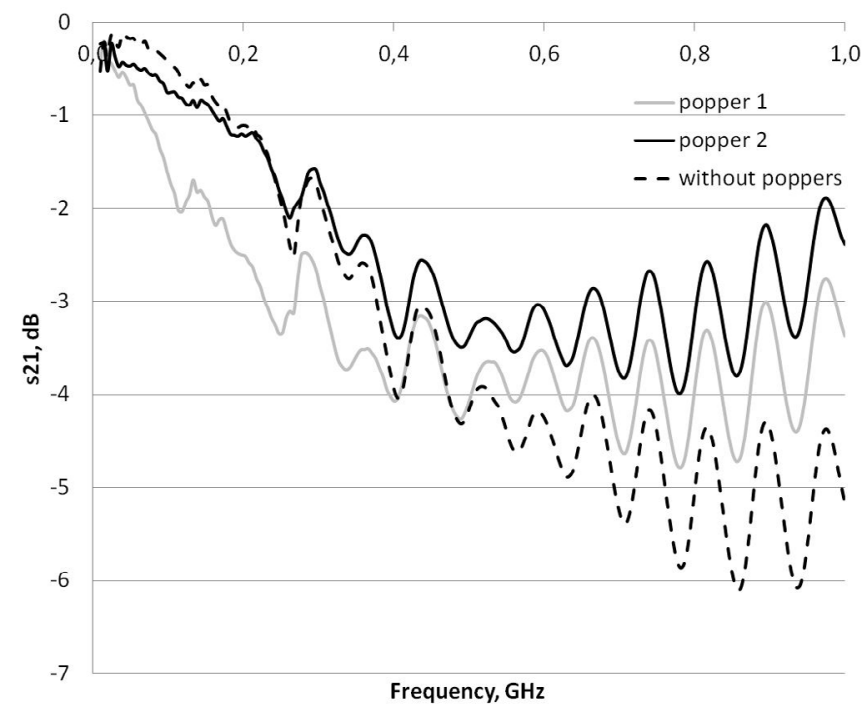

Figure 8. Real part of $s 21$ parameter of the tested structure

In the case of ideal transmission line, the output signal should be the same as the input signal. This means that the real 
part of the $s 11$ parameter (corresponding to the reflection value) should approach to minus infinity, while the real part of the s21 parameter (corresponding to the attenuation value) should be equal to zero irrespective of frequency. The level of signal reflections increases with increasing frequency (Fig. 7). The level of signal passing through the tested structure decreases with increasing frequency (Fig. 8). One of the parameters characterizing the attenuation of the signal as a function of frequency is "bandwidth," which is defined as the minimum frequency at which the signal attenuation is -3 $\mathrm{dB}$. The bandwidth of the textile line with poppers 2 is better than that with poppers 1 and reaches $350 \mathrm{MHz}$ (Fig. 8). The measurement results show that the line without poppers has worse transmission parameters than those with mounted poppers for high frequency signals. This is due to the large characteristic impedance of the coplanar transmission line used in research. Improvement of transmission properties of the line with mounted poppers is caused by decreased characteristic impedance of the line in place where poppers are mounted. Coplanar textile transmission lines are not suitable for cooperation with the tested poppers because of the large characteristic impedance of the line caused by large width of the electroconductive paths and large distances between them. A more appropriate transmission line is described in [32].

In turn, the obtained examples of eye diagrams, for different transmission speed of PRBS signal, are shown in Figures 9- 11.

In case of an ideal transmission line, the eye diagrams should be similar to the rectangle with maximum width and height. In this case, the eye is fully open. In the worst case, vertical and horizontal eye dimensions are zero. In this situation, eye is closed. It means that digital signal is not transmitted through the line. Eye diagrams presented in Figures 9-11 show (a)

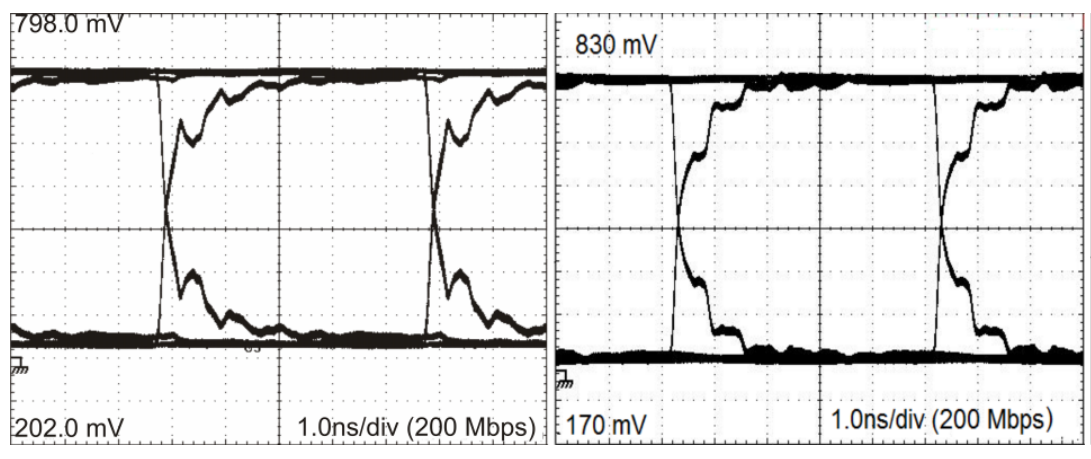

(c)

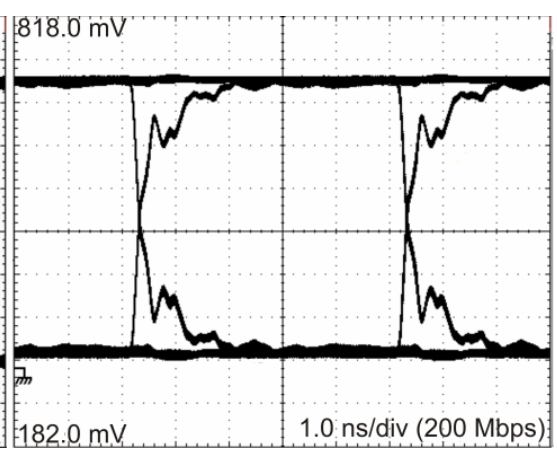

Figure 9. Eye diagrams for PRSB7 200 Mbps transmission: (a) popper 1, (b) without popper, and (c) popper 2.

(a)

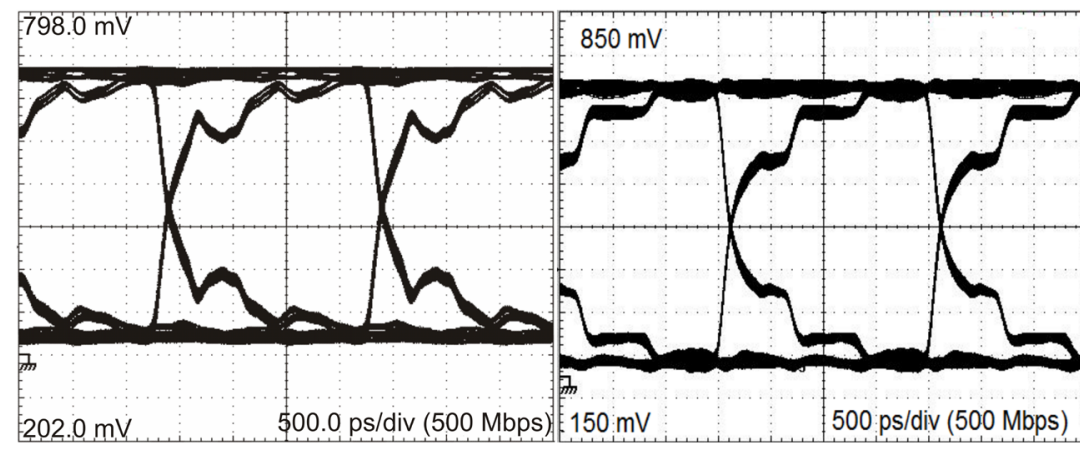

(b)

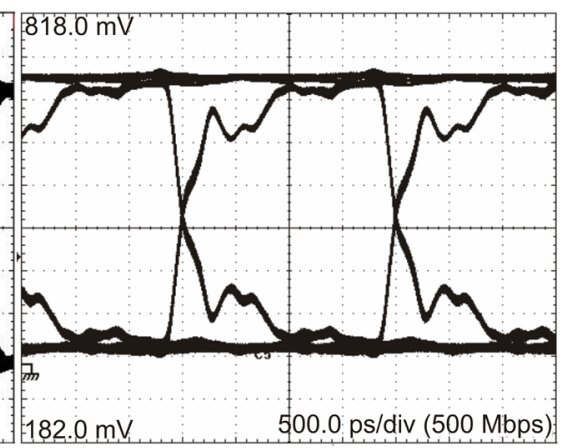

Figure 10. Eye diagrams for PRSB7 500 Mbps transmission: (a) popper 1, (b) without popper, and (c) popper 2.

(a)

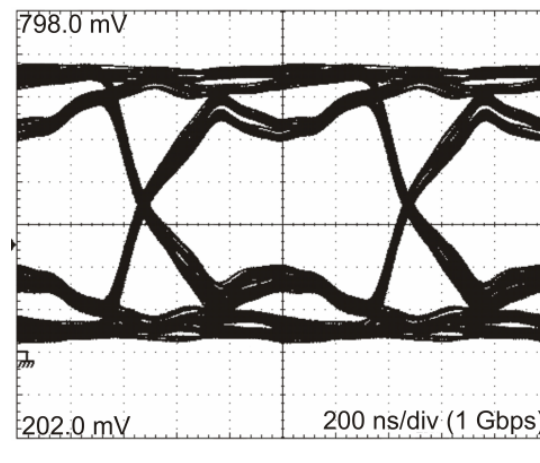

(b)

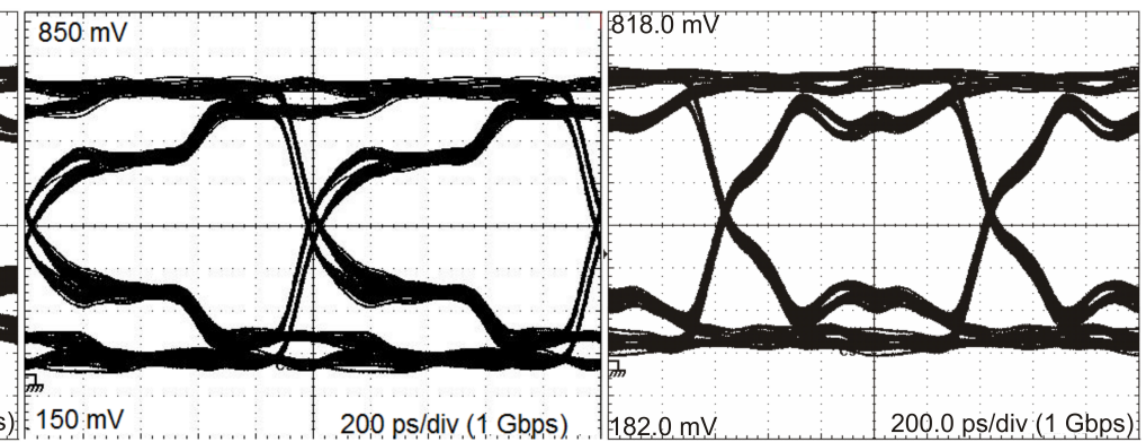

Figure 11. Eye diagrams for PRSB7 1 Gbps transmission: (a) popper 1, (b) without popper, and (c) popper 2. 
distortions of the transmitted digital signal but eye is still open. The transmitted signal can be, therefore, properly received.

Basic properties measured from eye diagrams are shown in Table 3.

Characteristic impedance of the poppers versus relative humidity at a constant temperature is shown in Figure 12. Another example (Fig. 13) shows characteristic impedance of the poppers versus temperature at constant absolute humidity of air surrounding poppers.

The analysis of influence of temperature and humidity surrounding poppers on the measured impedance was performed by using a non-parametric Kruskal-Wallis test. The hypothesis of equal average characteristic impedance measurements taken at three different temperatures was tested using this test (Fig. 14).

As a result of the test, the probability of $p=0.4551$ was obtained, which at a given level of significance of $\alpha=0.05$ leads to the acceptance of the null hypothesis assuming equality of average impedance in the tested groups. It means that there is no influence of temperature on the characteristic impedance of poppers.

As part of the study, the impact of ambient air humidity on the value of the characteristic impedance of the poppers was also examined. Obtained from Kruskal-Wallis test probability $p=$ 0.8689 , at a given level of significance of $\alpha=0.05$, also leads to the adoption of accepted null hypothesis of the equality of average impedance in the tested groups. It means that ambient relative humidity has no effect on the value of the characteristic impedance of poppers. Mean and standard deviation of the poppers' characteristic impedance at different relative humidity of air is shown in Figure 15.

\section{Conclusion}

Results obtained from the conducted research show that the two part of short coplanar textile transmission line connected with "spring" and "S-spring" poppers are capable of transmitting digital signal in digital systems where maximum frequency does not exceed $350 \mathrm{MHz}$.

Table 3 Basic parameters of the measured eye diagrams

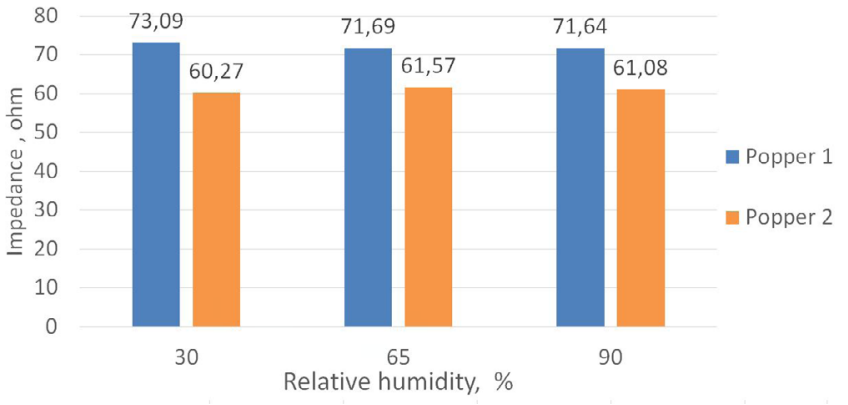

Figure 12. Characteristic impedance of the poppers at $20^{\circ} \mathrm{C}$ versus relative humidity [31]

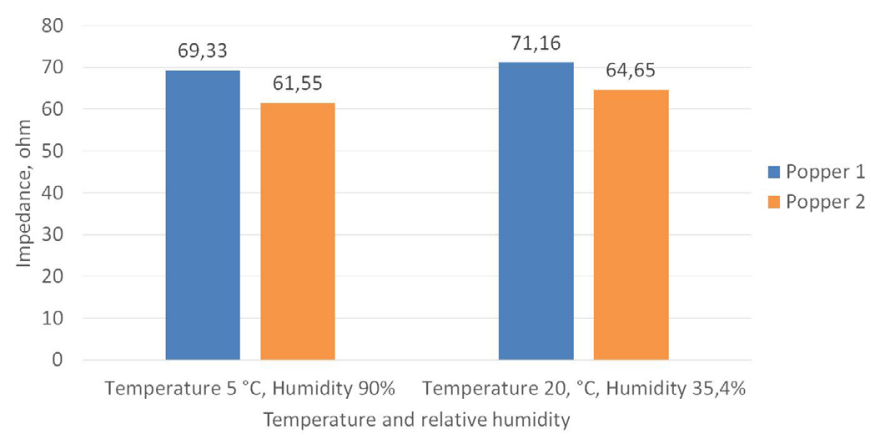

Figure 13. Characteristic impedance of the poppers at variable temperature and constant absolute humidity $w=6.15 \mathrm{~g} / \mathrm{m}^{3}[31]$

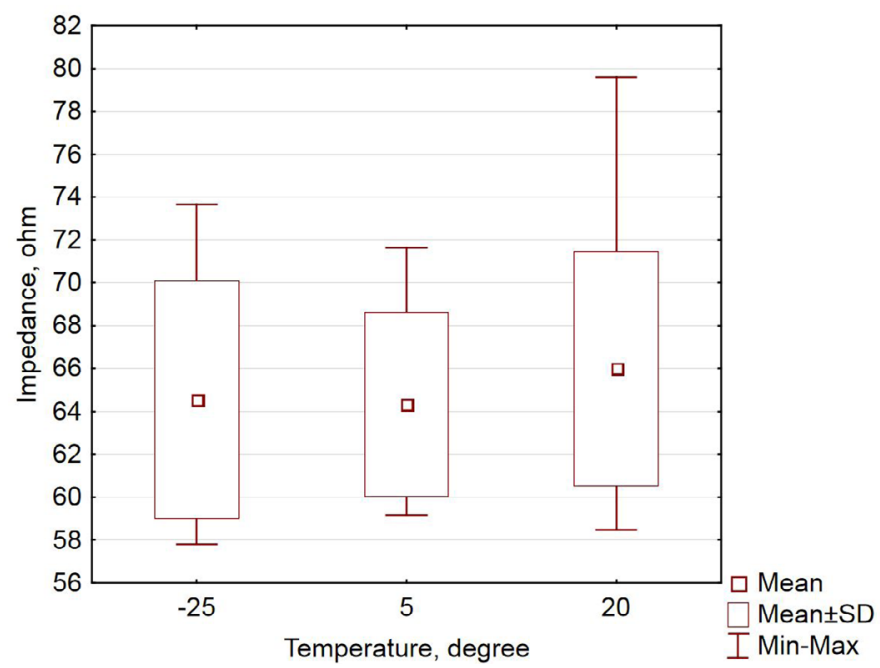

Figure 14. Mean and standard deviation of the impedance of both the poppers at different temperatures [31]

\begin{tabular}{|l|c|c|c|c|c|c|c|}
\hline \multirow{2}{*}{ Parameter } & \multirow{2}{*}{ Unit } & \multicolumn{2}{|c|}{ Line without poppers } & \multicolumn{3}{|c|}{ Line with poppers 1/2 } \\
\cline { 3 - 7 } & & $\begin{array}{c}\mathbf{2 0 0} \\
\mathbf{M b p s}\end{array}$ & $\begin{array}{c}\mathbf{5 0 0} \\
\mathbf{M b p s}\end{array}$ & $\mathbf{1} \mathbf{G b p s}$ & $\mathbf{2 0 0}$ Mbps & $\mathbf{5 0 0}$ Mbps & $\mathbf{1} \mathbf{G b p s}$ \\
\hline Eye amplitude & $\mathrm{mV}$ & 651.3 & 591.5 & $\mathbf{4 8 0 . 5}$ & $620.3 / 643.2$ & $\begin{array}{c}586.0 / \\
611.5\end{array}$ & $\mathbf{4 6 7 . 9 / 5 0 5 . 1}$ \\
\hline Vertical eye opening (1E-12) & $\mathrm{mV}$ & 617.4 & 506.7 & 284.3 & $581.8 / 622.4$ & $\begin{array}{c}525.5 / \\
565.3\end{array}$ & $284.7 / 334.7$ \\
\hline Total noise (1E-12) & $\mathrm{mV}$ & 33.9 & 84.8 & 196.2 & $38.5 / 20.8$ & $60.5 / 46.2$ & $183.2 / 170.4$ \\
\hline Horizontal eye opening (1E-12) & $\mathrm{ps}$ & 4960 & 1960 & 929.4 & $4950 / 4970$ & $1950 / 1960$ & $941.4 / 959.4$ \\
\hline Total jitter (1E-12) & $\mathrm{ps}$ & 38.0 & 44.1 & 70.6 & $50.7 / 34.0$ & $52.4 / 38.6$ & $58.6 / 40.6$ \\
\hline
\end{tabular}




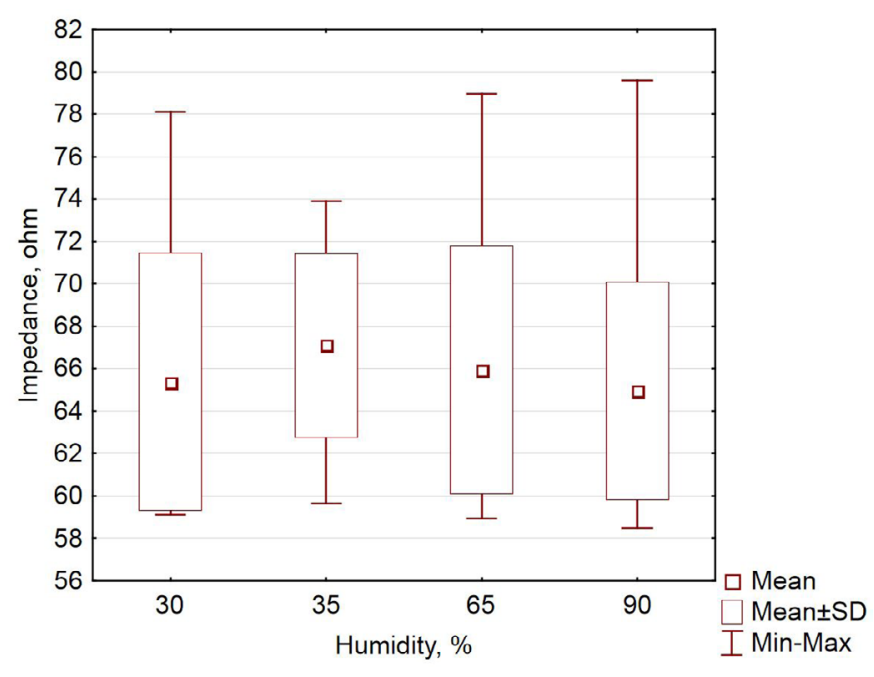

Figure 15. Mean and standard deviation of the impedance at different relative humidity [31]

Coplanar textile transmission lines are not suitable for cooperation with the tested poppers because of the large characteristic impedance of the line caused by large width of the electroconductive paths and large distances between them.

The obtained eye diagrams show that for 1 Gbps PRBS transmission, eye is still open. It allows one to accept the thesis about the possibility of error-free transmission of the signal through the tested structure. Of course, in order to verify the suitability of transmission line to transmit signal within a specified standard as USB, SATA, and so on, additional tests are required, using the so-called masks suitable for each standard.

The climate parameters such as temperature and humidity of the air surrounding the poppers do not significantly affect the value of their characteristic impedance. It was also found that for the tested poppers, the characteristic impedance is higher than the standard value of $50 \Omega$, which have conventional elements included in the high frequency measuring equipment and also in many conventional transmission systems. Poppers cooperation with such parts may result in increased level of signal reflections in the line and its distortion. Dimensions of the poppers also force size of the electroconductive paths on which they are placed. This is reflected in the transmission properties of the textile signal line limiting its upper value of the bandwidth. A broadband connection requires poppers as small as possible. Summing up obtained results indicate possibility of using poppers as electrical connectors in low- and mediumbandwidth signal transmission systems.

\section{References}

[1] Harms H., Amft O., Roggen D., Tröster G., (2009). Rapid prototyping of smart garments for activity-aware applications. Journal of Ambient Intelligence and Smart Environments 1(2), 1-15.

[2] Li L. et all, (2010). Design of Intelligent Garment with Transcutaneous Electrical Nerve Stimulation Function Based on the Intarsia Knitting Technique. Textile Research Journal, 80(3), 279-286.
[3] M. Stoppa, A. Chiolerio, (2014). Wearable Electronics and Smart Textiles: A Critical Review, Sensors, 14, 1195711992.

[4] L Van Langenhove. (Ed.). (2007). Smart Textiles for Medicine and Healthcare, Materials, Systems and Applications, (I ed.). Woodhead Publishing.

[5] Bouwstra S. et al., (2009). Smart Jacket Design for Neonatal Monitoring with Wearable Sensors, BSN '09 Proceedings of the 2009 Sixth International Workshop on Wearable and Implantable Body Sensor Networks, IEEE Computer Society Washington, DC, USA, 162-167.

[6] Amato G., Chessa S., Conforti F., Macerata A., Marchesi C.,(2005). Health Care Monitoring of Mobile Patients, ERCIM News, 60, 69-70.

[7] Carole A. et al., (2005). Development of Electronic Textiles to Support Networks, Communications, and Medical Applications in Future U.S. Military Protective Clothing Systems, IEEE Transactions on Information Technology in Biomedicine, 9(3), 402-406.

[8] Paradiso R., Wolter K., (2005). Wealthy - A Wearable Health Care System: New Frontier on E-Textile. MST News, 2, 10-11.

[9] Stempień Z., Rybicki E., Rybicki T., Leśnikowski J. (2015). Inkjet-printing deposition of silver electroconductive layers on textile substrates at low sintering temperature by using an aqueous silver ions-containing ink for textronic applications. Sensors and Actuators, B: Chemical, 224, 714-725.

[10] Kazani I., Declercq F., Scarpello M. L., Hertleer C., Rogier H., Vande Ginste D., De Mey G., Guxho G., L. Van Langenhove L., (2014), Performance study of screenprinted textile antennas after repeated washing. Autex Research Journal 14(2): 47-54

[11] Scarpello M. L., Kazani I, Hertleer C., Rogier H.,(2012), Stability and Efficiency of Screen-Printed Wearable and Washable Antennas, 11, 838-841

[12] Minyoung S., (2010). E-Textiles For Wearability: Review Of Integration Technologies. Retrieved 03 29, 2016, from http://www.textileworld.com/Articles/2010/April/Issue/ Etextiles_Feature.html.

[13] Agilent Technologies, AN 154, S-Parameter Design, Application Note

[14] On Semi, AND9075/D, Understanding Data Eye Diagram Methodology for Analyzing High Speed Digital Signals, Application Note.

[15] Leśnikowski J., Textile Transmission Lines in the Modern Textronic Clothes, (2011). FIBRES \& TEXTILES in Eastern Europe, 19(6), 89-93.

[16] Tokarska M., Leśnikowski J., Modeling of selected electric properties of textile signal lines using neural networks, (2014). Textile Research Journal, 84(3), 290-302.

[17] Chedid M. et al., (2007). Experimental analysis and modelling of textile transmission line for wearable applications, International Journal of Clothing Science and Technology, 19(1), 59-71.

[18] Cottet D. et all, (2003). Electrical Characterization of Textile Transmission Lines. IEEE Transactions on Advanced Packaging, 26(2), 182-190.

[19]Locher I, Tröster G.,(2007).Screen-printed Textile Transmission Lines, Textile Research Journal, 77(11), 837842. 
[20] Post E., et al., (2000). E-boidery: Design and fabrication of textile-based computing, IBM Systems Journal, 39, 840860.

[21] Kursun-Bahadir S., Effect of Textile Pretreatment Processes on the Signal Transferring Capability of Textile Transmission Lines, (2015). Fibres \& Textiles in Eastern Europe, 2,(110), 55-62.

[22] Dhawan A. et al., (2004). Woven Fabric-Based Electrical Circuits: Part II: Yarn and Fabric Structures to Reduce Crosstalk Noise in Woven Fabric-Based Circuits, Textile Research Journal, 74, 955-960.

[23] Dhawan A. et al., (2005). Fiber-Based Electrical and Optical Devices and Systems, Textile Progress, 36(2-3), 1-84.

[24] Jayoung Cho et al., (2007). Design and Evaluation of Textile-Based Signal Transmission Lines and Keypads for Smart Wear, Human-Computer Interaction, Part II, HCII, LNCS 4551, 1078-085.

[25] Locher I, Tröster G \& Kirstein T, (2005). From Smart Textiles to Wearable Systems, MST News, 2, 12-13.

[26] Breed G., (2003). Bit Error Rate: Fundamental Concepts and Measurement Issues, High Frequency Electronics, 1, 46-48.
[27] Nahman N. S. et al., (1980). Applications of time-domain methods to microwave measurements, Proc. Inst. Elec. Eng., 2(127), 99-106.

[28] Agilent Technologies, AN 1304-2 Time Domain Reflectometry Theory, Application Note, Literature Number 5966-4855E.

[29] Agilent Technologies , AN 1304-1 Evaluating Microstrip with Time Domain Reflectometry, Application Note, Literature Number 5968-0007E.

[30] Hsue Ch., (1997). Reconstruction of Nonuniform Transmission Lines from Time-Domain Reflectometry, IEEE Transactions on Microwave Theory and Techniques, 45(1), 32-38.

[31] Michalak Ł., (2013). Properties of the electrical connectors in the form of poppers (in polish: Właściwości złącz elektrycznych w postaci nap odzieżowych), dissertation thesis, Lodz University of Technology, Department of Architecture of Textiles.

[32] Leśnikowski J., (2015). New Kind of Textile Transmission Line with an Impedance of 50 Ohms, FIBRES \& TEXTILES in Eastern Europe, 23(2), 51-54. 